(2) Open Access Full Text Article

ORIGINAL RESEARCH

\title{
Systemic Cytokine Profiles of CD4+ T Lymphocytes Correlate with Clinical Features and Functional Status in Stable COPD
}

This article was published in the following Dove Press journal: International Journal of Chronic Obstructive Pulmonary Disease

\author{
Juliana Souza Uzeloto (1D' \\ Alessandra Choqueta de \\ Toledo-Arruda iD ${ }^{2}$ \\ Bruna Spolador de Alencar \\ Silva (iD) \\ Marjorie de Assis Golim (1D ${ }^{3}$ \\ Aline Márcia Marques Braz (D) ${ }^{3}$ \\ Fabiano Francisco de Lima $\mathbb{D}^{1}$ \\ Isis Grigoletto (D) ' \\ Ercy Mara Cipulo Ramos (D) \\ 'São Paulo State University (UNESP), \\ Faculty of Science and Technology, \\ Department of Physiotherapy, \\ Postgraduate Program in Physiotherapy, \\ Presidente Prudente, São Paulo, Brazil; \\ ${ }^{2}$ Department of Physiotherapy, Federal \\ University of Rio de Janeiro, Rio De \\ Janeiro, Brazil; ${ }^{3}$ São Paulo State \\ University (UNESP), Botucatu Medical \\ School, Postgraduate Program in \\ Research \& Development: Medical \\ Biotechnology, Blood Center, Flow \\ Cytometry Laboratory, Botucatu, São \\ Paulo, Brazil
}

Correspondence: Juliana Souza Uzeloto Email juliana_uzeloto@hotmail.com

\begin{abstract}
Aims: To evaluate the expressions of intracellular cytokines in CD4+ T lymphocytes and to investigate the correlation between biomarker expressions and clinical and functional characteristics of stable COPD patients.

Patients and Methods: Peripheral blood was collected from 36 COPD patients, and the expression of cytokines (IL-8, IL-13, IL-17, IL-6, IL-2, IL-10, and TNF- $\alpha$ ) in T lymphocytes CD4 + was investigated. In addition, lung function, dyspnea symptoms, quality of life, vital signs, body composition, level of physical activity, peripheral muscle strength, and functional capacity were assessed.

Results: Individuals with greater bronchial obstruction present a higher proportion of CD4 + IL$2+$ lymphocytes compared to individuals with less severe bronchial obstruction. We found a positive correlation between the expression of the cytokines IL-13, IL-17, IL-6, IL-2, IL-10, and TNF- $\alpha$ in CD4+ T lymphocytes. In addition, we found a positive correlation between CD4+ IL-10+ T lymphocytes and lower limb muscle strength and a negative correlation between CD4+ IL-8+ T lymphocytes and peripheral oxygen saturation and steps per day.
\end{abstract}

Conclusion: Systemic CD4+IL-2+, IL-8+, and IL-10+ $\mathrm{T}$ lymphocytes presented a correlation with clinical characteristics and functional status in stable COPD.

Keywords: chronic obstructive pulmonary disease, inflammation, phenotype, flow cytometry

\section{Introduction}

Chronic obstructive pulmonary disease (COPD) has a high prevalence worldwide and is associated with high morbidity and mortality. ${ }^{1}$ COPD is a heterogeneous disease characterized by airflow limitation due to abnormalities in the airways and lung parenchyma with persistent respiratory symptoms. It is mainly caused by inhalation of harmful particles and/or gases, such as tobacco smoking. ${ }^{2}$ With the progression of the disease, the original pulmonary inflammation becomes systemic causing profound changes in immune cell functions. ${ }^{3}$

Peripheral blood mononuclear cells (PBMC) comprise monocytes and lymphocytes (T, B and NK), important circulating cell populations that act as sensors and effectors of metabolic and inflammatory stresses. ${ }^{4}$ This action is orchestrated by immune signals conducted through cytokines in patients with COPD. ${ }^{5}$ Studies have shown increased signaling of proinflammatory cytokines in the plasma of patients with COPD, which directs and perpetuates chronic low-grade inflammation in this population, with consequent systemic damage. 5,6 
Besides plasma cytokine concentrations, intracellular analysis in specific cell populations may provide an even more detailed view of the complex chain of events occurring in the inflammatory process. ${ }^{7}$ Among the cell populations responsible for immune function in COPD, T lymphocytes, specifically, play an important role in stimulating or attenuating antibody production by B lymphocytes, or directly acting on antigens or infected cells, phagocytizing them. ${ }^{8,9}$ Clusters of differentiation (CD)4+ T helper 1 and 17 cells have been shown to accumulate in the lungs of patients with stable COPD, producing interferon- $\gamma$ (IFN- $\gamma$ ) and increasing inflammatory cells in the lungs. ${ }^{10,11}$ Although some investigations have been conducted, the response of CD4+ T cells in COPD is not yet fully understood. ${ }^{12-14}$

In addition, previous studies have suggested that changes in the expression of cytokines may be linked to the individual's ability to respond to physical and psychological stressors. That is, the inflammatory profile may present associations with clinical and functional aspects. ${ }^{15,16}$ However, the findings on systemic inflammation biomarkers and clinical characteristics of COPD are contradictory. ${ }^{15-21}$

In this way, it is essential to investigate the cell line responsible for synthesizing cytokines that orchestrate inflammation in stable COPD. ${ }^{22}$ In addition, exploring correlations not previously investigated between the intracellular inflammatory profile and clinical characteristics and functional status, may contribute to the management of this heterogeneous group of patients, with more promising results and better outcomes. ${ }^{23}$

Thus, the aims of the present study were to evaluate the expression of intracellular cytokines in $\mathrm{CD} 4+$ $\mathrm{T}$ lymphocytes and to investigate the relationship between the biomarker expression and clinical and functional characteristics of stable COPD patients.

\section{Patients and Methods}

\section{Participants}

This is a cross-sectional study, which included individuals with COPD recruited from medical clinics and outpatient clinics between 2018 and 2020. All volunteers were diagnosed according to the GOLD criteria (the presence of a postbronchodilator $\mathrm{FEV}_{1} / \mathrm{FVC}<0.70$ and/or dyspnea, chronic cough or sputum production, and/or a history of exposure to risk factors for the disease). ${ }^{2}$ The inclusion criteria were: absence of exacerbation in the three months prior to collection, absence of infectious and autoimmune diseases, and not

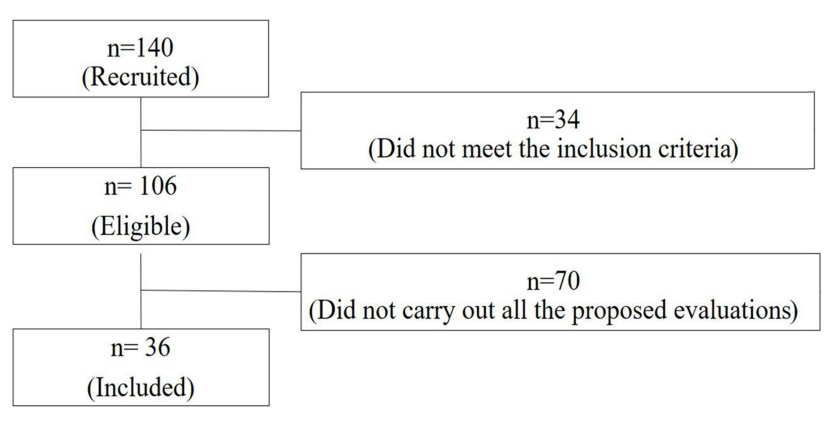

Figure I Flowchart of sample selection.

presenting respiratory diseases other than COPD. Seven patients who refused to perform blood collection and sixtythree patients whose samples were lost during processing were excluded from the analyses of the present study (Figure 1). This study was performed in accordance with the Declaration of Helsinki. This human study was approved by the Research Ethics Committee of São Paulo State University Presidente Prudente, São Paulo, Brazil - approval: 77909317.2.0000.5402. All adult participants provided written informed consent to participate in this study.

\section{Procedures}

Participants were familiarized with the study protocol and equipment before the experimental day. All assessments were performed in a room with a controlled temperature $\left(24 \pm 2^{\circ} \mathrm{C}\right)$. Participants were assessed for dyspnea, quality of life, and vital signs in a resting sitting position. For assessment of lung function, body composition, peripheral muscle strength, and functional exercise capacity tests, individuals were instructed to arrive at the laboratory a minimum of $2 \mathrm{~h}$ after a light meal and were asked to abstain from caffeinated beverages and alcohol for at least $12 \mathrm{~h}$ before the test sessions. Individuals were instructed to fast for $12 \mathrm{~h}$ prior to collection of peripheral blood for inflammation marker analyses.

The lung function, inflammation markers in peripheral blood, dyspnea, quality of life, vital signs, body composition, level of physical activity, peripheral muscle strength, and functional exercise capacity were evaluated. The procedures performed are listed below.

\section{Lung Function}

Lung function was verified by spirometry, to confirm the diagnosis of COPD, ${ }^{2}$ using a portable spirometer MIR Spirobank version 3.6. Data were interpreted based on the 
methods proposed by Neder and collaborators who investigated the Brazilian population. ${ }^{24}$

\section{Lymphocyte and Cytokine Staining}

A $5 \mathrm{~mL}$ sample of peripheral venous blood was collected from the antecubital vein in a heparinized tube. The sample was diluted 1:1 in culture medium (RPMI 1640 MediumSigma Aldrich) and monensin $(6.6 \mu \mathrm{L})$ and incubated for 4 hours at $37^{\circ} \mathrm{C}$ and $5 \% \mathrm{CO}_{2}$. The samples were divided into four analysis tubes ( $200 \mu \mathrm{L}$ of sample per tube) and the red blood cell population was lysed $(2 \mathrm{~mL}$ of Lyse solution, per tube, with incubation for 10 minutes in the dark at room temperature). The tubes were centrifuged $(500 \times g$ for 5 minutes), the supernatant discarded, and the cells washed with filtered saline before being centrifuged again $(500 \times$ $g$ for 5 minutes). CD3+ (10 $\mu \mathrm{L}$ Anti-CD3 FITC) and CD4+ (2 $\mu \mathrm{L}$ Anti-CD4 PERCP-CY5.5) were added to all tubes, which remained in incubation for 15 minutes at $4^{\circ} \mathrm{C}$. In sequence, the cells were washed twice with filtered saline. Two hundred fifty microliters of Cytofix/Cytoperm ${ }^{\circledR}$ (Golg fixation/permeabilization kit) were added per tube and the samples remained for 20 minutes at $4^{\circ} \mathrm{C}$ under incubation. After two washes with 1mL Perm/Wash (Golg fixation/permeabilization kit), the samples were resuspended with $100 \mu \mathrm{L}$ of Perm/Wash, stained with monoclonal antibodies specific for the cytokines of interest (Anti-interleukin (IL) -8 PE, IL-13 APC, IL-17 PE, IL-6 APC, IL-2 APC, IL-10 $\mathrm{PE}$, tumor necrosis factor alpha (TNF- $\alpha$ ) APC), and then incubated for 30 minutes at $4^{\circ} \mathrm{C}$. Next, the samples were washed twice with Perm/Wash and resuspended in $500 \mu \mathrm{L}$ of filtered saline for later reading on the flow cytometer. All reagents used in the analyses were obtained from Becton Dickinson, San Diego/CA.

\section{Flow Cytometry Analysis}

The FACSCalibur ${ }^{\circledR}$ 4-color cytometer (Beckton Dickinson) was used to acquire and analyze the samples, standardizing a total of $3 \times 10^{5}$ events collected per tube. The lymphocyte identification strategy was based on the parameters of size (forward scatter) versus cell granularity (side scatter), following the characterization of the auxiliary $\mathrm{T}$ lymphocyte $\mathrm{CD} 3$ $+/ \mathrm{CD} 4+$ phenotype. The cell population of interest (gate) was selected to evaluate the expression of intracytoplasmic cytokines stained with specific monoclonal antibodies (Anti-IL-8, IL-13, IL-17, IL-6, IL-2, IL-10, TNF-a). Isotypic controls and fluorescence minus one (FMO) were used to distinguish non-specific fluorescences. The analyses were performed using CellQuetPRO ${ }^{\circledR}$ and FlowJo ${ }^{\circledR}$ software, with the results expressed in percentage values (Figure 2).

\section{Dyspnea and Quality of Life}

The sensation of dyspnea was assessed using the Medical Research Council (MRC) dyspnea scale, ${ }^{25}$ and quality of life by the Chronic Respiratory Questionnaire (CRQ), validated for the Portuguese language. ${ }^{26}$

\section{Vital Signs}

Systolic blood pressure (SBP) and diastolic blood pressure (DBP) were measured in the left upper limb, with an analog sphygmomanometer and a stethoscope. Heart Rate (HR) and peripheral oxygen saturation $\left(\mathrm{SpO}_{2}\right)$ values were verified using a pulse oximeter (G-Tech Portable Oled Graph, Beijing, China).

\section{Body Composition}

In order to assess body composition, the electric bioimpedance Octopolar InBody 720 (Biospace, Seoul, Korea) was used. Skeletal muscle mass, body fat mass, and lean mass were evaluated. The data were electronically imported into Excel, using Lookin'Body software 3.0 (Biospace, Seoul, Korea).

\section{Physical Activity Level}

To analyze habitual daily physical activity, an Actigraph triaxial motion sensor, model GT3X (Actigraph LLC, Pensacola, FL) was used. The individuals were instructed to wear the equipment for seven days and remove it only when in contact with water (personal hygiene or water activities) and for night sleep. For data analysis, the specific software, ActiLife5 - Data Analysis Software by Actigraph, was used.

\section{Peripheral Muscle Strength}

Muscle strength was measured in the dominant hemibody using the Force Gauge ${ }^{\circledR}$ digital dynamometer, model FG$100 \mathrm{~kg}$ (Tobarra, Spain) and the results were expressed in Newtons $(\mathrm{N})$. The volunteers were instructed to perform elbow flexion, knee flexion, and extension movements. ${ }^{27}$

\section{Functional Exercise Capacity}

For the assessment of functional exercise capacity, participants performed the six-minute walk test (6MWT), according to the guidelines established by the American Thoracic Society. ${ }^{28}$ 

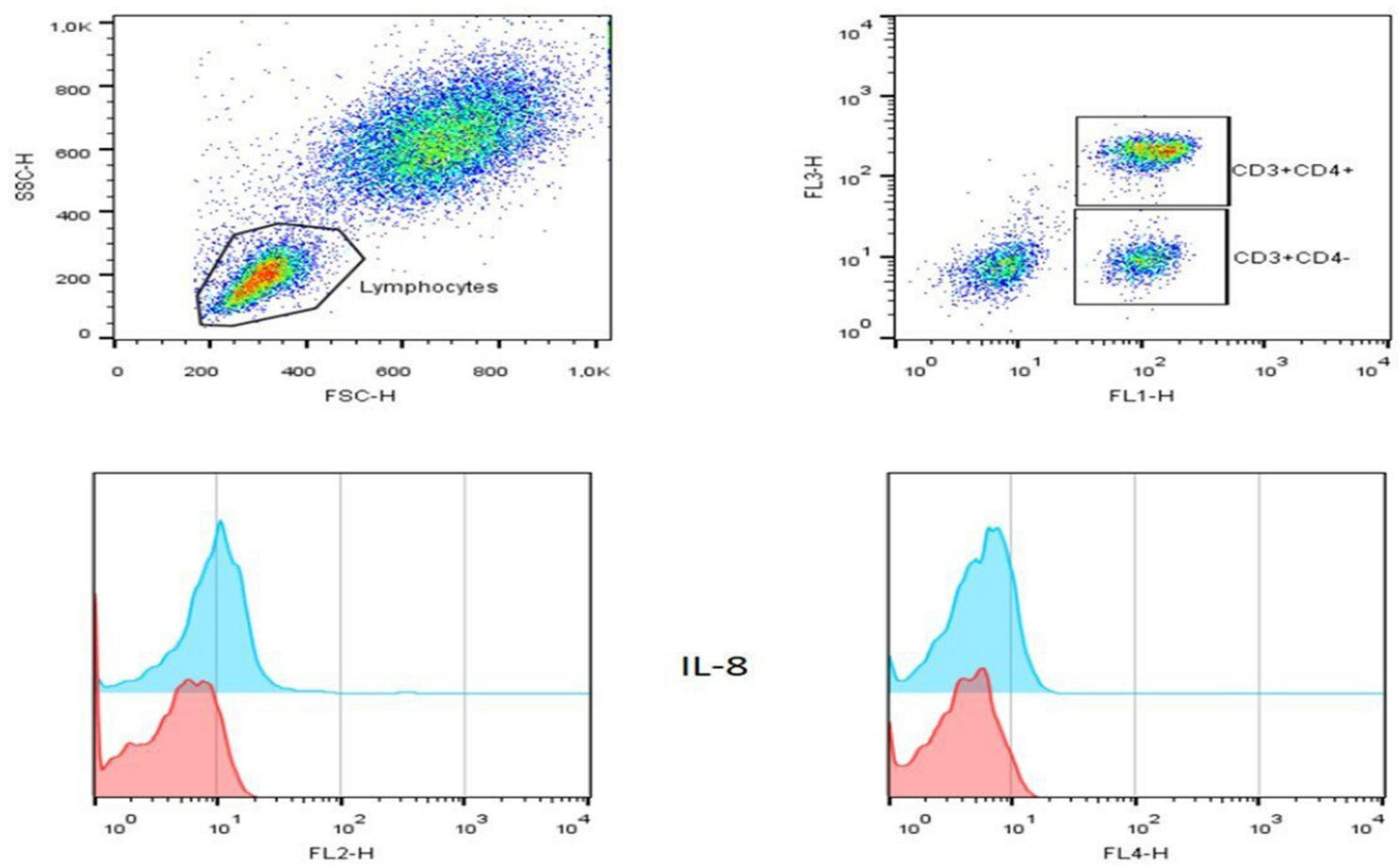

IL-13

Figure 2 Characterization of intracytoplasmic cytokines in helper T lymphocytes. Peripheral blood cell suspension staining with specific monoclonal antibodies Anti-CD3, CD4 (surface) and IL-8, IL-13, IL-17, IL-6, IL-2, IL-10, TNF-a (cytoplasmic). Characterized CD3+/CD4+ T lymphocyte phenotype (dot plots), the expression of intracellular cytokines was evaluated as demonstrated in histograms (negative control - red; expression of cytokine - blue).

\section{Statistical Analysis}

To assess the normality of the data, the Shapiro-Wilk test was applied. Comparisons were performed using pulmonary function stratifications, according to the GOLD categorization. ${ }^{2}$ GOLD subgroups 1 and 2 were combined, as well as GOLD subgroups 3 and 4, before being compared using the Student's $t$-test or Mann-Whitney test, according to the normality of the data. Correlation analyses were performed using the Pearson test for parametric data and the Spearman test for non-parametric data. To interpret the correlation coefficient, the following classifications were used: very strong ( $r \geq 0.9)$; strong $(0.9>r \geq 0.7)$; moderate $(0.7>\mathrm{r} \geq 0.5)$; or weak $(\mathrm{r}<0.5) .{ }^{31}$ In addition, for significant correlation results $(\mathrm{p}<0.05)$, linear regression was performed.

\section{Results}

A total of 36 volunteers with COPD were assessed in the study, 19 patients with $\mathrm{FEV}_{1}$ (\% of predicted) over 50\% and 17 under 50\%. GOLD 1 and 2 presented better lung function, $\mathrm{SpO}_{2}$, steps per day, and functional exercise capacity than GOLD 3 and 4. Similar symptoms, quality of life, body composition, muscle strength, and functional capacity were observed among the GOLD subgroups. Characteristics of all participants are shown in Table 1.

Table 2 shows the cytokine expression of the sample. When comparing the proportion of TCD4 + lymphocytes that expressed cytokines, a 5.61\% higher mean IL-2+ was observed in patients with more severe obstruction $(\mathrm{p}=$ 0.03). The proportions of IL- $8+$, IL13 +, IL-17 +, IL-6 + , IL-10 +, and TNF- $\alpha+$ in $\mathrm{T}$ lymphocytes were not distinguished between patients with different degrees of airway obstruction ( $>>0.05)$.

Figure 3 presents linear regression graphs of significant positive correlations between the expression of IL-13, IL17, IL-6, IL-2, IL-10, and TNF- $\alpha$ in CD4+ T lymphocytes $(p<0.05)$. No significant correlations were observed in the analyses of IL-8 with the other cytokines.

Figure 4 presents the correlations between cytokine expression in CD4+ $\mathrm{T}$ lymphocytes and clinical and functional characteristics. Significant correlations were observed between IL-10 expression and muscle strength of knee flexors $(\mathrm{p}=0.003 ; \mathrm{r}=0.493)$ and knee extensors $(\mathrm{p}=0.014$; $\mathrm{r}=0.413$ ) (Figure 4A). In addition, negative correlations were observed between IL- 8 expression and steps per day $(\mathrm{p}=0.043 ; \mathrm{r}=-0.339)$ and IL-8 and peripheral oxygen saturation $(\mathrm{p}=0.031 ; \mathrm{r}=-0.361)$ (Figure 4B). Finally, a correlation 
Table I Participant Characteristics

\begin{tabular}{|c|c|c|c|c|c|}
\hline & $\begin{array}{l}\text { Total Sample } \\
(n=36)\end{array}$ & $\begin{array}{l}\text { GOLD I and } 2 \\
(n=19)\end{array}$ & $\begin{array}{l}\text { GOLD } 3 \text { and } 4 \\
(n=17)\end{array}$ & $\mathbf{p}$ & $\begin{array}{l}\text { Mean Difference (95\% } \\
\mathrm{Cl})\end{array}$ \\
\hline Male/Female n (\%) & $19(52.8) / 17(47.2)$ & $9(47.4) / 10(52.6)$ & $10(58.8) / 7(4 \mid .2)$ & 0.49 & \\
\hline Age (years) & $69.67 \pm 7.3$ & $69.79 \pm 8.05$ & $69.53 \pm 6.61$ & 0.92 & $0.26(-4.76$ to 5.28$)$ \\
\hline Body weight (kg) & $67.12 \pm 14.1$ & $65.93 \pm 15.58$ & $68.44 \pm 12.57$ & 0.60 & $-2.51(-12.17$ to 7.16$)$ \\
\hline Height (m) & $1.63 \pm 0.09$ & $1.60 \pm 0.08$ & $1.66 \pm 0.09$ & 0.06 & $-0.06(-0.11$ to 0.00$)$ \\
\hline \multicolumn{6}{|l|}{ Lung function } \\
\hline FEV (\% of predicted) & $52.81 \pm 20.6$ & $68.79 \pm 13.73$ & $34.94 \pm 8.56$ & $<0.00 I^{*}$ & 33.85 (25.99 to $4 I .7 I)$ \\
\hline FVC (\% of predicted) & $72.42 \pm 18.8$ & $82.68 \pm 15.15$ & $60.94 \pm 15.8$ & $<0.00 I^{*}$ & 21.74 (11.25 to 32.23$)$ \\
\hline $\mathrm{FEV}_{\mathrm{l}} / \mathrm{FVC}(\%)$ & $53.48 \pm 11.76$ & $61.54 \pm 6.35$ & $44.46 \pm 9.69$ & $<0.001 *$ & 17.07 (11.58 to 22.56$)$ \\
\hline \multicolumn{6}{|l|}{ Dyspnea } \\
\hline$M R C$ & $3(2-4)$ & $3.5(2-4)$ & $3(2-5)$ & 0.61 & $-0.24(-1.17$ to 0.69$)$ \\
\hline \multicolumn{6}{|l|}{ Quality of life } \\
\hline CRQ & $19.88 \pm 5.1 \mid$ & $21.16 \pm 4.25$ & $|8.45 \pm 5.7|$ & 0.11 & $2.72(-0.67$ to 6.10$)$ \\
\hline \multicolumn{6}{|l|}{ Vital signs } \\
\hline $\mathrm{SBP}(\mathrm{mmHg})$ & $120.56 \pm 15.85$ & $121.58 \pm 16.42$ & $|19.4| \pm \mid 5.6$ & 0.69 & $2.17(-8.7 \mid$ to 13.05$)$ \\
\hline $\mathrm{DBP}(\mathrm{mmHg})$ & $80(70-90)$ & $80(70-90)$ & $80(70-90)$ & 0.56 & $-2.04(-9.13$ to 5.05$)$ \\
\hline HR (beats/minute) & $74.5(68.25-81.75)$ & $74(67-8 I)$ & $75(69.5-82.5)$ & 0.24 & -4.35 (-11.67 to 2.98$)$ \\
\hline RF (breaths/minute) & $18(16-20)$ & $20(16-20)$ & $16(15-20)$ & 0.75 & $0.39(-2.11$ to 2.89$)$ \\
\hline $\mathrm{SpO}_{2}(\%)$ & $94.39 \pm 3.24$ & $96.05 \pm 1.58$ & $92.53 \pm 3.62$ & $<0.001 *$ & 3.52 ( 1.66 to 5.38$)$ \\
\hline \multicolumn{6}{|l|}{ Body composition } \\
\hline Fat mass $(\mathrm{kg})$ & $24.12 \pm 9.56$ & $23.69 \pm 10.6$ & $24.58 \pm 8.6 I$ & 0.79 & $-0.89(-7.55$ to 5.78$)$ \\
\hline Skeletal muscle mass (kg) & $22.9 \pm 4.92$ & $22.23 \pm 5.15$ & $23.61 \pm 4.72$ & 0.42 & $-1.37(-4.78$ to 2.03$)$ \\
\hline Lean mass $(\mathrm{kg})$ & $40.11 \pm 7.77$ & $38.97 \pm 8.08$ & $41.32 \pm 7.47$ & 0.38 & $-2.35(-7.71$ to 3.01$)$ \\
\hline \multicolumn{6}{|l|}{ Physical activity level } \\
\hline Steps per day & $\begin{array}{l}4080.5 \\
(2606.93-5599.21)\end{array}$ & $\begin{array}{l}4436.14 \\
(2788.43-6 \mid 12.7 I)\end{array}$ & $\begin{array}{l}3093.7 \mid \\
(|356.29-4552.4|)\end{array}$ & $0.03 *$ & $\begin{array}{l}2381.37(282.51 \text { to } \\
4480.23)\end{array}$ \\
\hline \multicolumn{6}{|l|}{ Muscle strength } \\
\hline Elbow flexors (N) & $87.4(64.4-123.2)$ & $82.9(61.35-115.9)$ & $104.6(64.6-127.8)$ & 0.66 & $-6.95(-38.32$ to 24.42$)$ \\
\hline Knee flexors $(\mathrm{N})$ & $124.63 \pm 43.5$ & $121.36 \pm 40.37$ & $128.09 \pm 47.58$ & 0.65 & $-6.74(-37.02$ to 23.55$)$ \\
\hline Knee extensors $(\mathrm{N})$ & $162.2(106.2-223.2)$ & 166.7 (I05.65-205.8) & $155.8(96.5-228)$ & 0.64 & $13.75(-45.17$ to 72.67$)$ \\
\hline \multicolumn{6}{|l|}{ Functional exercise capacity } \\
\hline 6MWT distance $(\mathrm{m})$ & $439.56 \pm 123.35$ & $480.58 \pm 113.13$ & $393.71 \pm 121.05$ & $0.03 *$ & 86.87 (7.55 to 166.20$)$ \\
\hline
\end{tabular}

Notes: Data expressed as mean \pm standard deviation or median (range $25 \%-75 \%$ ), according to normality. * $<0.05$ when comparing the ratings by GOLD.

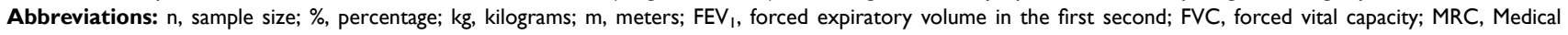
Research Council dyspnea scale; CRQ, Chronic Respiratory Questionnaire; SBP, systolic blood pressure; DBP, diastolic blood pressure; mmHg, millimeters of mercury; HR, heart rate; $\mathrm{RF}$, respiration frequency; $\mathrm{SpO}_{2}$, peripheral oxygen saturation; $\mathrm{N}$, newton; 6MWT, six-minute walk test.

Table 2 Expression of Cytokines in CD4+ T Lymphocytes in the Total Sample and in Subgroups Classified by GOLD

\begin{tabular}{|l|l|l|l|l|l|}
\hline & Total Sample $(\mathbf{n = 3 6 )}$ & GOLD I and 2 (n=I9) & GOLD 3 and 4 (n=I7) & $\mathbf{p}$ & Mean Difference (95\% CI) \\
\hline IL-8 (\%) & $4.59(1.82-23.22)$ & $2.64(1.5-22.47)$ & $5.35(2.82-26.28)$ & 0.60 & $-3.59(-17.42$ to I0.24) \\
IL-13 (\%) & $10.14 \pm 4.46$ & $9.34 \pm 4.74$ & $11.04 \pm 4.09$ & 0.26 & $-1.69(-4.71$ to I.32) \\
IL-17 (\%) & $0.12(0.06-0.22)$ & $0.11(0.06-0.28)$ & $0.12(0.06-0.2)$ & 0.35 & $0.05(-0.06$ to 0.17$)$ \\
IL-6 (\%) & $10.75 \pm 5.02$ & $10.23 \pm 5.25$ & $11.32 \pm 4.84$ & 0.52 & $-1.09(-4.52$ to 2.35$)$ \\
IL-2 (\%) & $21.18 \pm 7.72$ & $18.53 \pm 6.94$ & $24.15 \pm 7.66$ & $0.03 *$ & $-5.61(-10.55$ to -0.67$)$ \\
IL-10 (\%) & $0.14(0.08-0.24)$ & $0.14(0.06-0.24)$ & $0.14(0.09-0.27)$ & 0.44 & $-0.05(-0.17$ to 0.08$)$ \\
TNF- $\alpha(\%)$ & $8.42 \pm 3.78$ & $8.13 \pm 4.56$ & $8.75 \pm 2.76$ & 0.63 & $-0.62(-3.21$ to I.97) \\
\hline
\end{tabular}

Notes: Data expressed as mean \pm standard deviation or median (range $25 \%-75 \%$ ), according to normality. * $<0.05$ when comparing the ratings by GOLD. Abbreviations: IL, interleukin; TNF- $\alpha$, tumour necrosis factor alpha; \%, percentual. 

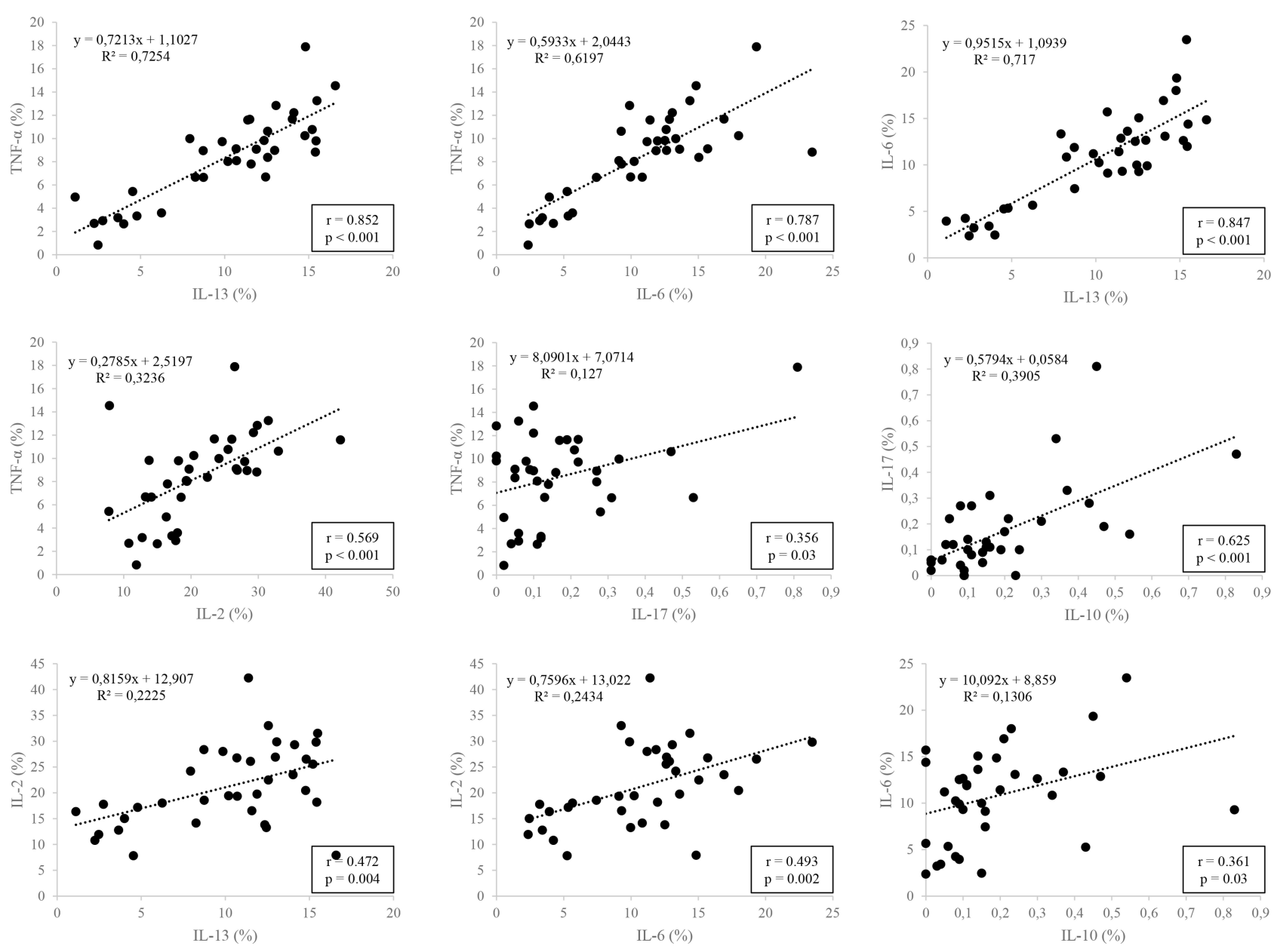

Figure 3 Graphical representation of linear regression between cytokine expressions in CD4+ T lymphocytes.

was also observed between the expression of IL-17 and FVC (\% of predicted) $(\mathrm{p}=0.047 ; \mathrm{r}=0.333)$ (Figure $4 \mathrm{C})$.

Quality of life, body composition, and functional exercise capacity were not related to the proportion of lymphocytes expressing the evaluated cytokines (Supplementary Table).

\section{Discussion}

In the present study, individuals with more severe bronchial obstruction presented a higher proportion of CD4+ IL-2+ T lymphocytes. The study also demonstrated correlations between pro (IL-13, IL-6, IL-17, IL-2, and TNF- $\alpha$ ) and anti-inflammatory (IL-10) cytokines in CD4+ T lymphocytes. Furthermore, to the best of our knowledge, this is the first study to show positive correlations between CD4+T IL-10+ T lymphocytes and muscle strength, and negative correlations between CD4+ IL-8+T lymphocytes and steps per day and peripheral oxygen saturation, as well as CD4+ IL-17+ T lymphocytes and forced vital capacity in patients with stable COPD.
Systemic inflammation in COPD has been extensively investigated. ${ }^{30}$ Meta-analyses have confirmed that COPD patients, even when clinically stable, present high plasma concentrations of several factors such as leukocytes, C-reactive protein (CRP), IL- 6 , IL - 8 , fibrinogen, and TNF- $\alpha$ characterizing a condition of systemic inflammation. ${ }^{31,32}$ Furthermore, many studies have explored the association of cytokines with the lung function of patients with stable COPD. ${ }^{30,33-35}$

Previous studies have shown correlations between plasma levels of TNF- $\alpha$, IL-1 $\beta$, IL-6, IL-10, IL-15, and IL-17 with the severity of bronchial obstruction. ${ }^{33-35}$ Bradford et al, in a combined analysis of two large studies, including 2123 subjects from "COPDGene" and 1117 subjects from "SPIROMICS", with analysis of six cytokines (IL-2, IL-6, IL-8, IL-10, TNF- $\alpha$, and IFN- $\gamma$ ), found an association of four biomarkers (IL-6, IL-8, and IL-10) with worse airflow obstruction. ${ }^{30}$

However, the inflammatory response is the result of complex connections of many cells and different molecules, 


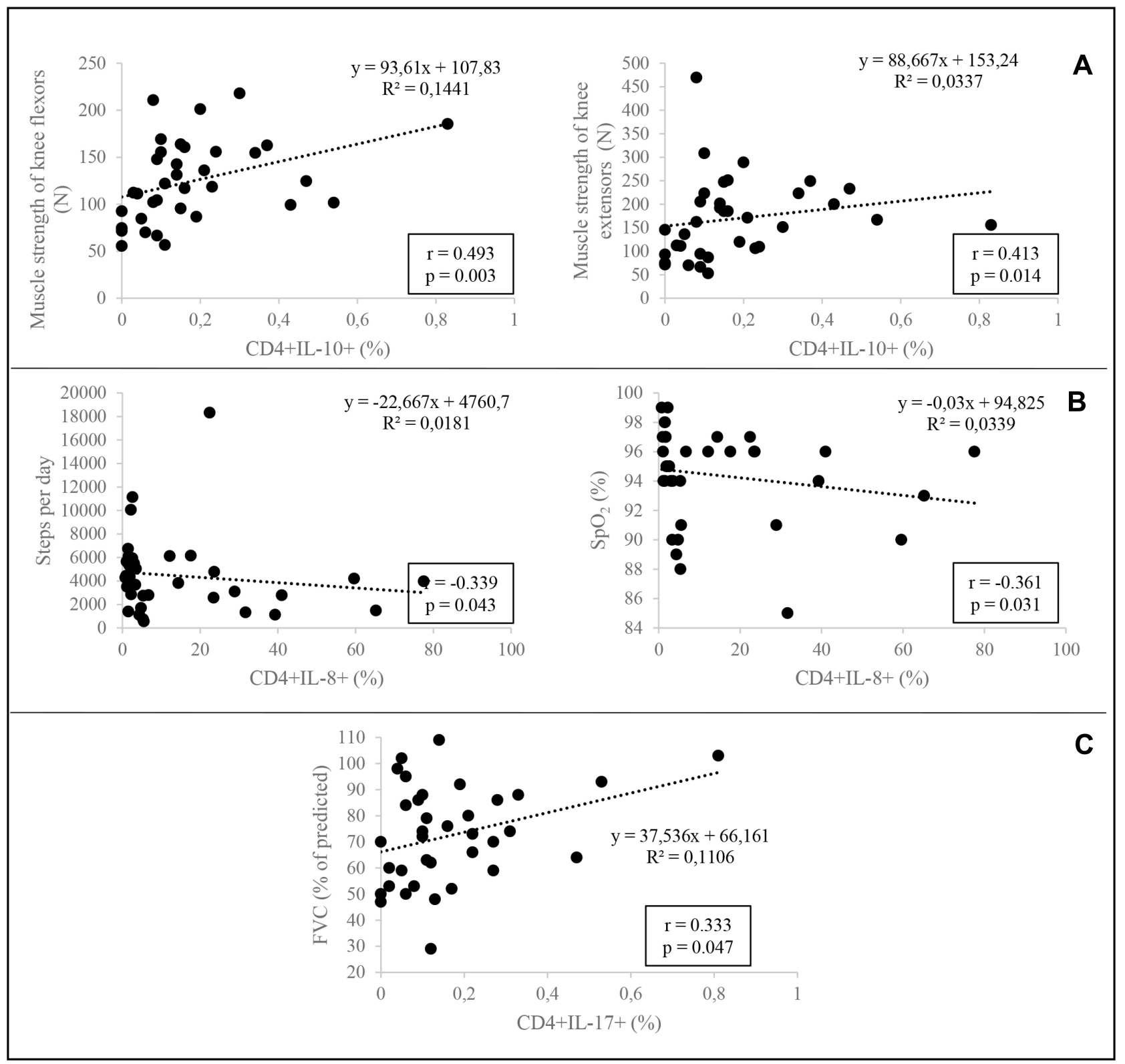

Figure 4 Graphical representation of linear regression between cytokine expressions in CD4+ T lymphocytes and clinical and functional characteristics. (A) presents the correlations between CD4+IL-10+ and muscle strength expression; (B) is between CD4+IL-8+ and steps per day and peripheral oxygen saturation; (C) is the correlation between CD4+IL-I7+ and FVC (\% of predicted).

which may justify some contradictions observed in the studies described above that evaluated cytokines at plasma levels. Knowledge of the cell line responsible for the synthesis of cytokines is essential for the precise definition of the chain of events that leads to the analysis of a biological function. In this way, intracellular analyses have emerged to explore the specific behavior of the expression of inflammation markers and, consequently, clarify the broad process that occurs in diseases. ${ }^{36}$

In the present study, we identified positive correlations in the proportion of CD4+ T lymphocytes that expressed IL-2,
IL-6, IL-10, IL-13, IL-17, and TNF- $\alpha$, in the total sample. Studies have shown that both TNF- $\alpha^{37}$ and IL- ${ }^{38}$ promote inflammatory reactions and IL- 6 seems to be linked to the pathological mechanisms of COPD. ${ }^{39}$ The findings about IL13 are conflicting, but in summary, this cytokine appears to be more associated with the mucus-producing cell metaplasia in COPD. ${ }^{39}$ Furthermore, evidence indicates that IL-17 can induce the expression of innumerable pro-inflammatory cytokines, and that its production is controlled by regulatory cytokines, with emphasis on IL-10, ${ }^{40}$ which may explain the correlation between them observed in the present study. These 
associations could encourage future research on the exploration and understanding of intracellular mechanisms, since if not controlled, the signaling performed by this range of cytokines, by cells of the immune system, may amplify inflammatory responses.

We found a correlation between CD4+IL-17+ and FVC that was not observed in a previous study. ${ }^{12}$

In the present study, we observed a higher proportion of CD4+ IL-2+ T lymphocytes in individuals with more severe bronchial obstruction. It is known that IL-2 triggers the proliferation and differentiation of $\mathrm{T}$ cells, being crucial for the defense of pathogens. ${ }^{41}$

Corroborating our results, Knobloch et al, observed that patients with COPD with inflammation present more intense IL-2 + production by CD4 + lymphocytes, compared to healthy individuals and smokers. However, Knobloch et al point out that despite increased expression of IL-2, people with COPD may not respond with increased $\mathrm{T}$ cell proliferation. ${ }^{42}$ Thus, despite the increase in IL-2 in the most severe COPD, there may not be a proliferative response of lymphocytes in the same proportion in these individuals, which compromises their defense system. In addition, the authors ${ }^{42}$ hypothesize that bacteria partially block T-cell proliferation more intensely in COPD, and with greater intensity in patients with greater obstruction, resulting in immunosuppressive mechanisms.

Systemic manifestations in COPD are diverse and affect patients differently, making them a heterogeneous population, ${ }^{43}$ in which individuals are distinguished in relation to biological, clinical, and functional characteristics. ${ }^{44}$ In an attempt to identify subgroups of patients, in order to act more precisely, the correlation of biomarkers with clinical and functional characteristics of patients with stable COPD has been explored. However, studies that investigated inflammatory biomarkers using plasma analysis and clinical characteristics such as sex, ${ }^{18}$ dyspnea, ${ }^{17}$ fatigue, ${ }^{17}$ pain, ${ }^{17}$ and exacerbation risk $^{19}$ found no associations between these variables.

In the present study, we observed a positive correlation between the proportion of CD4+ IL-10+ T cells and the strength of the knee flexor and extensor muscles. It is known that IL-10 is considered an anti-inflammatory cytokine, as it has the ability to suppress the pro-inflammatory response and, therefore, limit tissue damage from the inflammatory process, contributing to homeostasis. ${ }^{45}$ In addition, the benefits of muscle strength, specifically of the lower limbs, for COPD patients are widely known. ${ }^{46,47}$ However, to the best of our knowledge, this is the first study to show a correlation between CD4+ IL10+ T cells and muscle strength in stable COPD. This finding reinforces the importance of peripheral muscles not only for functionality but also as a possible factor for suppressing the systemic inflammatory response.

In addition, negative correlations were observed between CD4+ IL-8 T lymphocytes and peripheral oxygen saturation and the mean number of steps taken per day. The cytokine IL- 8 is one of the most active and widespread biological molecules, with a pro-inflammatory role, as it has chemotactic properties for immune cells. ${ }^{37}$ In addition, IL-8 is also associated with increased mucus production and remodeling processes that affect the airways. ${ }^{37}$ In an in vitro experiment, Dziurla et al showed that oxygen deprivation can facilitate inflammatory reactions, ${ }^{48}$ which may explain the negative correlations found in the present study, that is, lower oxygen values in peripheral blood, and higher proportions of CD4+ $\mathrm{T}$ lymphocytes that express IL-8+. In addition, peripheral oxygen saturation showed a positive correlation with the mean number of steps taken per day $(\mathrm{p}=0.001 ; \mathrm{r}=0.534)$, indicating a direct link between these variables.

It is clear that the cross-sectional nature of this research is limiting and does not allow us to clarify the relation between cause and effect. Furthermore, the investigation of a single cell population (CD4+ T lymphocytes) is not able to reveal the interaction of other populations throughout the systemic inflammation process that occurs in stable COPD. Therefore, future prospective research, involving several cells, is necessary to assist in understanding biomarkers of systemic inflammation in patients with stable COPD and their association with clinical and functional characteristics, to assist clinicians in decision-making.

The novel findings of this study are the profile of cytokines in CD4+ T lymphocytes and the correlation with clinical and functional characteristics in stable COPD. The main findings were a higher proportion of $\mathrm{CD} 4+\mathrm{IL}-2+$ $\mathrm{T}$ lymphocytes in patients with greater bronchial obstruction. In addition, the data indicate a link between IL-13, IL-6, IL-2, and TNF- $\alpha$ signaling in CD4+ T lymphocytes. Finally, there is a positive correlation between $\mathrm{CD} 4+$ IL-10+ $\mathrm{T}$ lymphocytes and lower limb muscle strength and a negative correlation between CD4+ IL-8+ T lymphocytes and peripheral oxygen saturation and steps per day. These findings may contribute to understanding of the role of systemic inflammation in the pathogenesis and progression of COPD and, particularly, provide guidance for clinical decisions. 


\section{Acknowledgments}

This work was supported by the São Paulo Research Foundation (FAPESP), Grant \#2017/10145-7 and \#2018/ 04870-3, and Post Graduate Program of UNESP which had no involvement in the study design, collection, analysis and interpretation of data, writing of the report, or in the decision to submit the article for publication. We are grateful to Dionei Ramos, Paulo Roberto Gomes and James Falconi Belchior, who provided practical assistance during the project.

\section{Disclosure}

The authors report no conflicts of interest in this work.

\section{References}

1. Iheanacho I, Zhang S, King D, Rizzo M, Ismaila AS. Economic burden of Chronic Obstructive Pulmonary Disease (COPD): a systematic literature review. Int $J$ Chron Obstruct Pulmon Dis. 2020;15:439-460. doi:10.2147/COPD.S234942

2. GOLD 2020. Global strategy for diagnosis, management and prevention of COPD- 2020 UPDATE; 2020. Available from: www.gold copd.org. Accessed April 22, 2020.

3. Halper-Stromberg E, Yun JH, Parker MM, et al. Systemic markers of adaptive and innate immunity are associated with chronic obstructive pulmonary disease severity and spirometric disease progression. $\mathrm{Am}$ J Respir Cell Mol Biol. 2018;58(4):500-509. doi:10.1165/rcmb.20170373OC

4. Agarwal AR, Kadam S, Brahme A, et al. Systemic immuno-metabolic alterations in chronic obstructive pulmonary disease (COPD). Respir Res. 2019;20(1):171. doi:10.1186/s12931-019$1139-2$

5. Barnes PJ. Inflammatory mechanisms in patients with chronic obstructive pulmonary disease. J Allergy Clin Immunol. 2016;138 (1):16-27. doi:10.1016/j.jaci.2016.05.011

6. Barnes PJ. Targeting cytokines to treat asthma and chronic obstructive pulmonary disease. Nat Rev Immunol. 2018;18(7):454-466. doi:10.1038/s41577-018-0006-6

7. Song Y, Nigro J, Yu L, et al. Secreted and intracellular cytokines are complementary measures for human monocytes treated with Toll-like receptor agonists. J Immunol Methods. 2019;464:131-137. doi:10. 1016/j.jim.2018.11.003

8. Sileikiene V, Laurinaviciene A, Lesciute-Krilaviciene D, Jurgauskiene L, Malickaite R, Laurinavicius A. Levels of CD4+ $\mathrm{CD} 25+\mathrm{T}$ regulatory cells in bronchial mucosa and peripheral blood of chronic obstructive pulmonary disease indicate involvement of autoimmunity mechanisms. Adv Respir Med. 2019;87(3):159-166. doi:10.5603/ARM.2019.0023

9. Mesquita Júnior D, Araújo JAP, Catelan TTT, et al. Sistema imunitário - parte II: fundamentos da resposta imunológica mediada por linfócitos T e B. Rev Bras Reumatol Engl Ed. 2010;50:552-580. doi:10.1590/S0482-50042010000500008

10. Grumelli S, Corry DB, Song L-Z, et al. An immune basis for lung parenchymal destruction in chronic obstructive pulmonary disease and emphysema. PLoS Med. 2004;1(1):e8. doi:10.1371/journal. pmed.0010008

11. Di Stefano A, Caramori G, Gnemmi I, et al. $T$ helper type 17-related cytokine expression is increased in the bronchial mucosa of stable chronic obstructive pulmonary disease patients. Clin Exp Immunol. 2009;157(2):316-324. doi:10.1111/j.13652249.2009.03965.x
12. Paats MS, Bergen IM, Hoogsteden HC, van der Eerden MM, Hendriks RW. Systemic CD4+ and CD8+ T-cell cytokine profiles correlate with GOLD stage in stable COPD. Eur Respir J. 2012;40 (2):330-337. doi:10.1183/09031936.00079611

13. Xu W, Li R, Sun Y. Increased IFN-gamma-producing Th17/Th1 cells and their association with lung function and current smoking status in patients with chronic obstructive pulmonary disease. BMC Pulm Med. 2019;19(1):137. doi:10.1186/s12890-019-0899-2

14. Selvarajah S, Todd I, Tighe PJ, et al. Multiple circulating cytokines are coelevated in chronic obstructive pulmonary disease. Mediators Inflamm. 2016;2016:3604842. doi:10.1155/2016/3604842

15. Byun MK, Cho EN, Chang J, Ahn CM, Kim HJ. Sarcopenia correlates with systemic inflammation in COPD. Int $J$ Chron Obstruct Pulmon Dis. 2017;12:669-675. doi:10.2147/COPD.S130790

16. Ferrari R, Caram LM, Faganello MM, Sanchez FF, Tanni SE, Godoy I. Relation between systemic inflammatory markers, peripheral muscle mass, and strength in limb muscles in stable COPD patients. Int J Chron Obstruct Pulmon Dis. 2015;10:1553-1558. doi:10.2147/COPD.S85954

17. Nguyen HQ, Herting JR, Pike KC, et al. Symptom profiles and inflammatory markers in moderate to severe COPD. BMC Pulm Med. 2016;16(1):173. doi:10.1186/s12890-016-0330-1

18. Sharanya A, Ciano M, Withana S, Kemp PR, Polkey MI, Sathyapala SA. Sex differences in COPD-related quadriceps muscle dysfunction and fibre abnormalities. Chron Respir Dis. 2019;16:1479973119843650. doi:10.1177/1479973119843650

19. Celli BR, Anderson JA, Brook R, et al. Serum biomarkers and outcomes in patients with moderate COPD: a substudy of the randomised SUMMIT trial. BMJ Open Respir Res. 2019;6(1):e00431. doi:10.1136/bmjresp-2019-000431

20. Lee JS, Rosengart MR, Kondragunta V, et al. Inverse association of plasma IL-13 and inflammatory chemokines with lung function impairment in stable COPD: a cross-sectional cohort study. Respir Res. 2007;8(1):64. doi:10.1186/1465-9921-8-64

21. Nuñez A, Marras V, Harlander M, et al. Association between routine blood biomarkers and clinical phenotypes and exacerbations in chronic obstructive pulmonary disease. Int $J$ Chron Obstruct Pulmon Dis. 2020;15:681-690. doi:10.2147/COPD.S240720

22. Simpson JL. Airway inflammation in COPD: is it worth measuring and is it clinically meaningful? Respirology. 2020;25(1):47-48. doi: $10.1111 /$ resp. 13656

23. Stockley RA, Halpin DMG, Celli BR, Singh D. Chronic obstructive pulmonary disease biomarkers and their interpretation. Am J Respir Crit Care Med. 2019;199(10):1195-1204. doi:10.1164/rccm.2018101860 SO

24. Neder JA, Andreoni S, Castelo-Filho A, Nery LE. Reference values for lung function tests: I. Static volumes. Braz J Med Biol Res. 1999;32:703-717. doi:10.1590/S0100-879X1999000600006

25. Kovelis D, Segretti NO, Probst VS, Lareau SC, Brunetto AF, Pitta F. Validação do modified pulmonary functional status and dyspnea questionnaire e da escala do medical research council para o uso em pacientes com doença pulmonar obstrutiva crônica no Brasil. J Bras Pneumol. 2008;34:1008-1018. doi:10.1590/S1806-371320080 01200005

26. Moreira GL, Pitta F, Ramos D, et al. Versão em português do chronic respiratory questionnaire: estudo da validade e reprodutibilidade. $J$ Bras Pneumol. 2009;35:737-744. doi:10.1590/S1806-37132009000800004

27. Ramos EM, de Toledo-arruda AC, Fosco LC, et al. The effects of elastic tubing-based resistance training compared with conventional resistance training in patients with moderate chronic obstructive pulmonary disease: a randomized clinical trial. Clin Rehabil. 2014;28(11):1096-1106. doi:10.1177/0269215514527842

28. Holland AE, Spruit MA, Troosters T, et al. An official European Respiratory Society/American Thoracic Society technical standard: field walking tests in chronic respiratory disease. Eur Respir J. 2014;44(6):1428-1446. doi:10.1183/09031936.00150314 
29. Mukaka MM. Statistics corner: a guide to appropriate use of correlation coefficient in medical research. Malawi Med J. 2012;24 (3):69-71.

30. Bradford E, Jacobson S, Varasteh J, et al. The value of blood cytokines and chemokines in assessing COPD. Respir Res. 2017;18 (1):180. doi:10.1186/s12931-017-0662-2

31. Su B, Liu T, Fan H, et al. Inflammatory markers and the risk of chronic obstructive pulmonary disease: a systematic review and meta-analysis. PLoS One. 2016;11(4):e0150586-e0150586. doi:10. 1371/journal.pone.0150586

32. Yao Y, Zhou J, Diao X, Wang S. Association between tumor necrosis factor- $\alpha$ and chronic obstructive pulmonary disease: a systematic review and meta-analysis. Ther Adv Respir Dis. 2019;13:17 53466619866096. doi:10.1177/1753466619866096

33. Singh S, Verma SK, Kumar S, et al. Correlation of severity of chronic obstructive pulmonary disease with potential biomarkers. Immunol Lett. 2018;196:1-10. doi:10.1016/j.imlet.2018.01.004

34. Silva BSA, Lira FS, Ramos D, et al. Severity of COPD and its relationship with IL-10. Cytokine. 2018;106:95-100. doi:10.1016/j. cyto.2017.10.018

35. Jiang S, Shan F, Zhang Y, Jiang L, Cheng Z. Increased serum IL-17 and decreased serum IL-10 and IL-35 levels correlate with the progression of COPD. Int J Chron Obstruct Pulmon Dis. 2018;13: 2483-2494. doi:10.2147/COPD.S167192

36. Ansari AA, Mayne AE. Cytokine analysis by intracellular staining. Methods Mol Med. 2002;72:423-435.

37. Vitenberga Z, Pilmane M, Babjoniševa A. The evaluation of inflammatory, anti-inflammatory and regulatory factors contributing to the pathogenesis of COPD in airways. Pathol Res Pract. 2019;215 (1):97-105. doi:10.1016/j.prp.2018.10.029

38. Abbas AK, Trotta E, Marson A, Bluestone JA. Revisiting IL-2. Biol Therap Prospect. 2018;3(25).

39. Brightling CE, Saha S, Hollins F. Interleukin-13: prospects for new treatments. Clin Exp Allergy. 2010;40(1):42-49.

40. Le Rouzic O, Pichavant M, Frealle E, Guillon A, Si-Tahar M, Gosset P. Th17 cytokines: novel potential therapeutic targets for COPD pathogenesis and exacerbations. Eur Respir J. 2017;50(4).
41. Liao W, Lin JX, Leonard WJ. IL-2 family cytokines: new insights into the complex roles of IL-2 as a broad regulator of T helper cell differentiation. Curr Opin Immunol. 2011;23(5):598-604. doi:10.10 16/j.coi.2011.08.003

42. Knobloch J, Chikosi SJ, Yanik S, Rupp J, Jungck D, Koch A. A systemic defect in Toll-like receptor 4 signaling increases lipopolysaccharide-induced suppression of IL-2-dependent T-cell proliferation in COPD. Am J Physiol Lung Cell Mol Physiol. 2016;310(1):L24-39. doi:10.1152/ajplung.00367.2014

43. Castaldi PJ, Boueiz A, Yun J, et al. Machine learning characterization of COPD subtypes: insights from the COPDGene study. Chest. 2020;157(5):1147-1157. doi:10.1016/j.chest.2019.11.039

44. Corlateanu A, Mendez Y, Wang Y, Garnica RJA, Botnaru V, Siafakas N. Chronic obstructive pulmonary disease and phenotypes: a state-of-the-art. Pulmonology. 2020;26(2):95-100. doi:10.1016/j. pulmoe.2019.10.006

45. Couper KN, Blount DG, Riley EM. IL-10: the master regulator of immunity to infection. J Immunol. 2008;180(9):5771-5777. doi:10.40 49/jimmunol.180.9.5771

46. Marquis K, Debigaré R, Lacasse Y, et al. Midthigh muscle cross-sectional area is a better predictor of mortality than body mass index in patients with chronic obstructive pulmonary disease. Am J Respir Crit Care Med. 2002;166(6):809-813. doi:10.1164/ rccm.2107031

47. Swallow EB, Reyes D, Hopkinson NS, et al. Quadriceps strength predicts mortality in patients with moderate to severe chronic obstructive pulmonary disease. Thorax. 2007;62(2):115-120. doi:10. 1136/thx.2006.062026

48. Dziurla R, Gaber T, Fangradt M, et al. Effects of hypoxia and/or lack of glucose on cellular energy metabolism and cytokine production in stimulated human CD4+ T lymphocytes. Immunol Lett. 2010;131 (1):97-105. doi:10.1016/j.imlet.2010.02.008

International Journal of Chronic Obstructive Pulmonary Disease

Dovepress

\section{Publish your work in this journal}

The International Journal of COPD is an international, peer-reviewed journal of therapeutics and pharmacology focusing on concise rapid reporting of clinical studies and reviews in COPD. Special focus is given to the pathophysiological processes underlying the disease, intervention programs, patient focused education, and self management protocols. This journal is indexed on PubMed Central, MedLine and CAS. The manuscript management system is completely online and includes a very quick and fair peer-review system, which is all easy to use. Visit http://www.dovepress.com/testimonials.php to read real quotes from published authors.

Submit your manuscript here: https://www.dovepress.com/international-journal-of-chronic-obstructive-pulmonary-disease-journal 